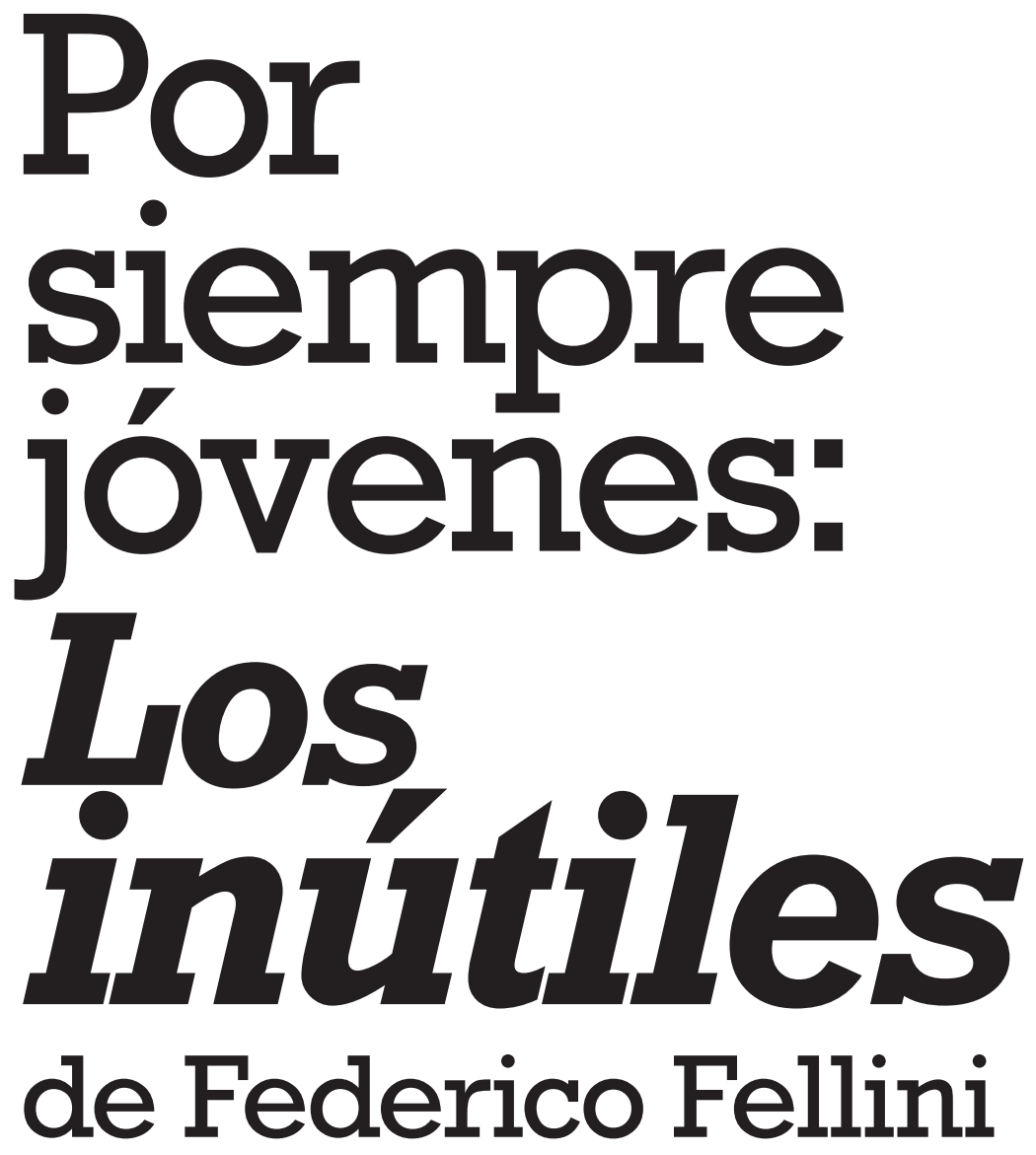

Provisto de una sensibilidad lírica muy particular, Federico Fellini nos deleitó con varios de los personajes más memorables del cine italiano. En esta oportunidad, quien escribe se detiene a hablar de aquel grupo de jóvenes que comparten la vida en Los inútiles (1953).

"Hasta el liceo, nunca me había planteado el problema de qué haría en la vida; no conseguía proyectarme en el futuro. Pensaba en la profesión como algo que no es posible evitar, como la misa del domingo. Nunca me dije: ‘De mayor seré...!'. No me parecía que fuera a convertirme en mayor, y en el fondo no me equivocaba demasiado". (Fellini, 1999)

\title{
Diego Arévalo
}

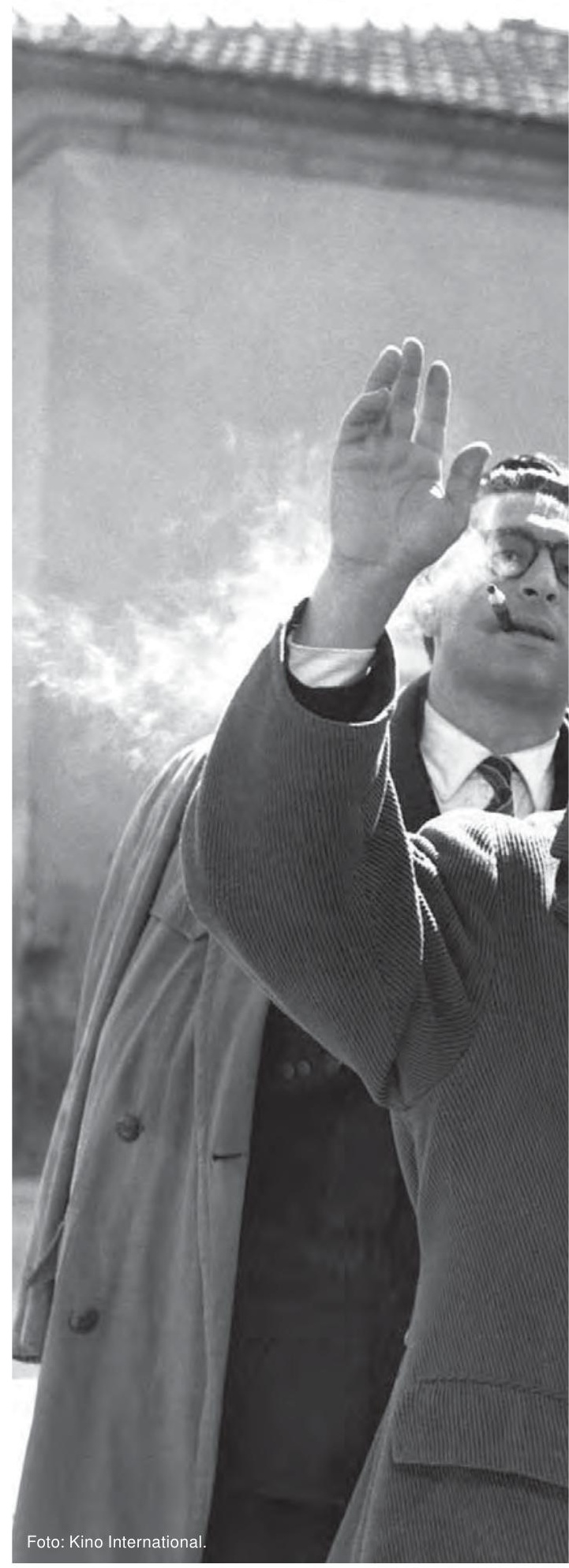

\section{I vitelloni, de Federico Fellini}

"Adiós Guido", dice la voz de Federico Fellini. En realidad, pareciera que lo dijera Moraldo - álter ego del autor en la película- en la escena final, cuando se despide del niño que trabaja en 


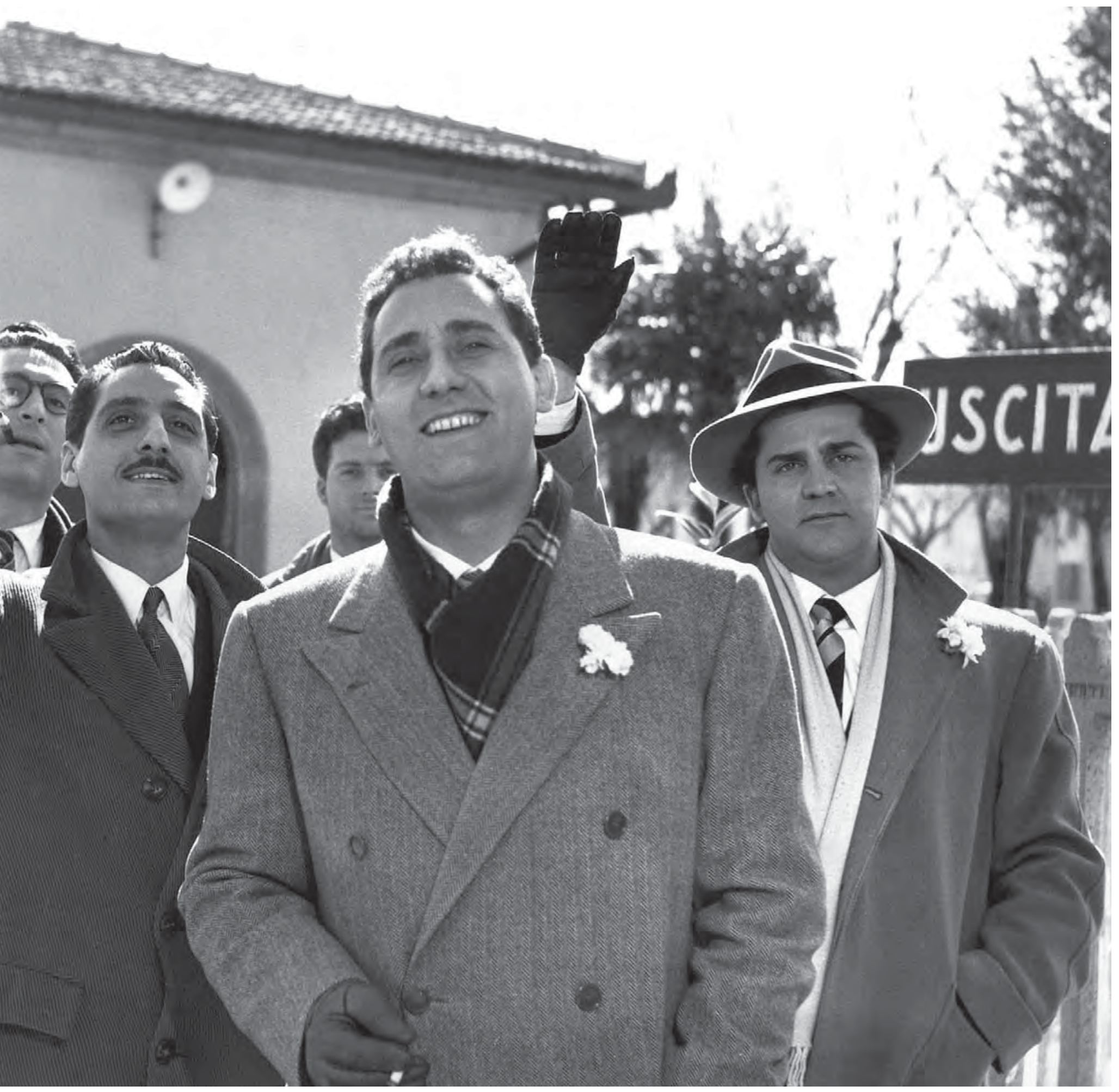

el ferroviario. Pero no. Fellini monta su propia voz para despedirse nuevamente, solo que esta vez desde el mundo de la ficción, del pueblo natal que lo vio crecer y fruto de sus inspiraciones cinematográficas: Rímini. Este momento, cuando Moraldo se aleja por las vías del tren, resulta cru- cial para la vida del realizador, pues marca el fin de un periodo de su propia historia, el del joven solitario que sueña con la ciudad de Roma mientras es testigo de los acontecimientos de su pueblo. Esta etapa se cierra con un viaje, pero abre el verdadero camino del cineasta, Fellini abandona el nido para convertirse en uno de los autores más grandes de la historia del ciney nosotros somos testigos de ello.

\section{Historia y personajes}

¿Qué es un vitellone? Aunque se tradujo como Los inútiles, en senti- 


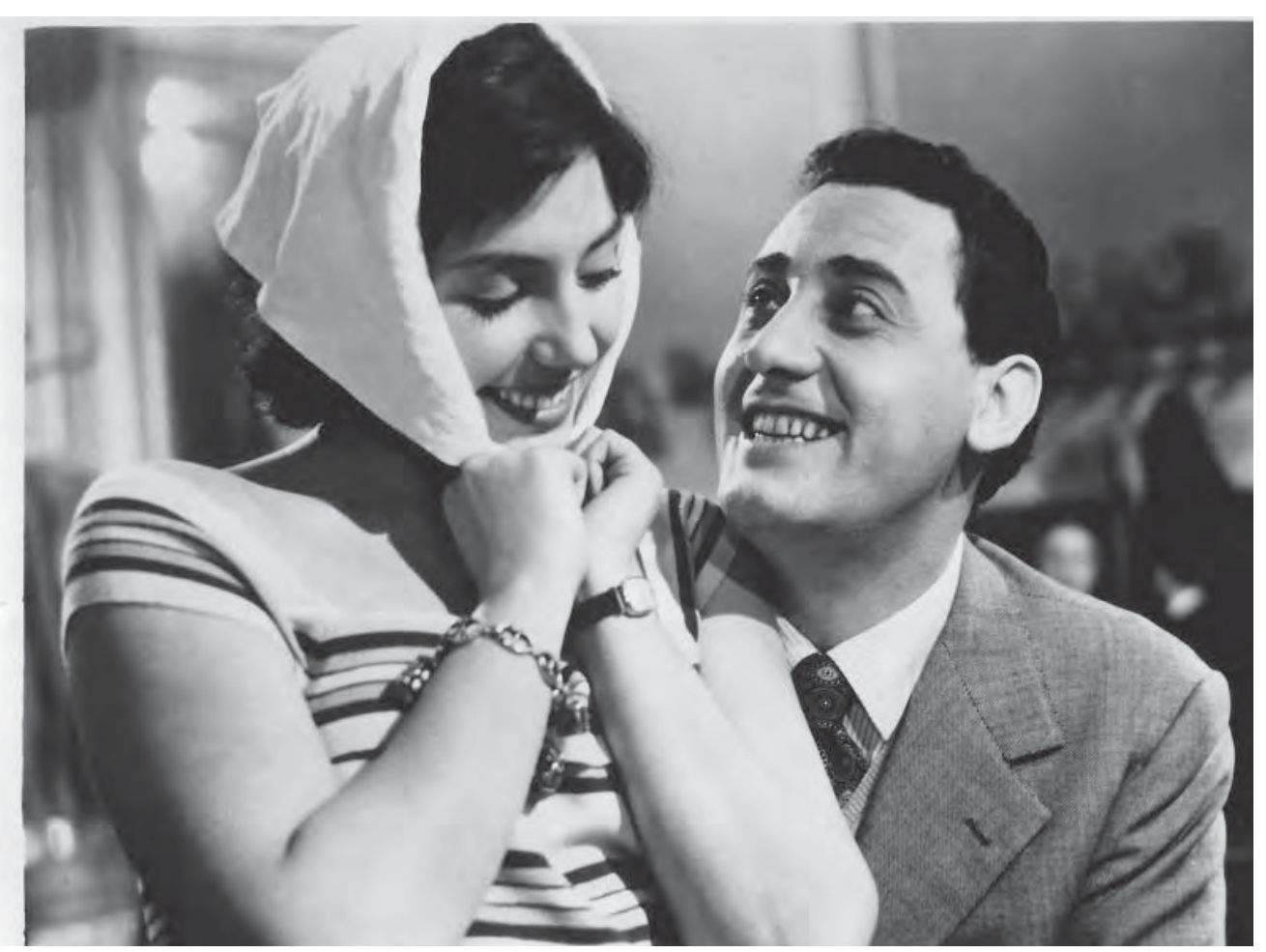

do literal vitello significa 'ternero o becerro'. Estos terneros son cinco y ya están bastante creciditos. No trabajan y siguen viviendo en casas de los padres sin pensar en su futuro. Se reúnen en diferentes escenarios como son las fiestas, el muelle, la plaza y no hacen otra cosa que, usando unajerga local, pasarla 'hueviando'. A pesar de que cada quien posee su propia individualidad, juntos forman un solo cuerpo inseparable. Al inicio de la película vemos la plaza del pueblo de noche y vacía. Los inútiles, pletóricos de vida, irrumpen en ella como sombras. Están abrazados y entonan una canción: rompen con la calma del pueblo junto con una delas hermosas melodías de Nino Rota. Inicio fugaz y vital, como la propia juventud, que busca sintetizar una etapa de la vida por la que, si tenemos suerte, casi todos pasamos. I vitelloni (1953) es una película sobre las experiencias de la juventud, sus consecuencias y el aprendizaje que conllevan. Los muchachos se abren a la vida desperdigando todo su ímpetu. Sus celebracionesyllantos; su falta deescrúpulos y la toma de conciencia; sus ilusiones y la triste realidad; sus máscaras y vidas privadas. El más inconsciente de todos ellos, Fausto, aprenderá la lección a la fuerza. Moraldo, en cambio, optará por darle vuelta a la página y emprenderá un viaje. Esta película será para algunos de nosotros como un espejo; porque cuando uno ve una película de Fellini, es inevitable que no acabe viendo su propia vida, de alguna manera.

Dicen que Fellini nunca fue un vitellone, que no pudo ser posible pues partió a Roma cuando tenía 19 años y no le dio tiempo para convertirse en uno de esos vagos de esquina. Sin embargo, cada uno de ellos es Fellini. En primer lugar tenemos a Fausto: el líder y guía espiritual del grupo, como lo dice el propio narrador dela película. Un verdadero don Juan que busca huir de casa apenas se entera de que Sandra, su novia, está embarazada. A pesar de las travesuras e insolencias de este personaje, no resulta difícil compararlo con el propio autor. Es bastante conocida la relación que Fellini tenía con las mujeres a pesar de estar casado con la Massina, su esposa y actriz de algunas de sus películas más emblemáticas. También tenemos a Alberto, el lacra' del grupo que es presentado mientras trata de gorrear unos cigarros y no hace otra cosa que romperse a reír cuando se entera de que el padre de Fausto le ha propinado una paliza a este. Alberto podría representar el lado más infantil y juguetón del director. Luego tenemos a Leopoldo, el intelectual del grupo.
Aspira convertirse en un dramaturgo y está fascinado con el mundo del espectáculo, pero prefiere pasarla perdiendo el tiempo con sus amigos. Él podría representar al hombre con la sensibilidad artística que habita en Fellini. También tenemos a Ricardo, hermano del propio director, el cantante del grupo. Este personaje no presenta ningún tipo de conflicto. Es, al parecer, el más correcto de todos y el menos llamativo. Por último, pero no menos importante (todo lo contrario), tenemos a Moraldo. Curioso nombre para el más tímido, observador y solitario del grupo. Él es el primer álter ego de Fellini y el único que parece tomar conciencia de lo que sucede en su entorno. Su ánimo melancólico se puede ver cuando, en la estación, observa cómo el tren se pierde en el horizonte. O también cuando está sentado solo, de madrugada, en una banca. Un niño de pies inquietos - Guido- llega y lo acompaña. Juntos, comienzan a ver y hablar de las estrellas. Ingenuo e inocente a más no poder (como algunos de los personajes de Fellini) cree en las cosas que le dice el pícaro de Fausto. En un momento del filme bebe agua y disfruta de ella. El agua en las películas de Fellini está relacionada con la pureza. Precisamente, el rostro de Moraldo expresa eso: la gracia de los gestos de las personas que aún no han perdido la inocencia porque todavía no ha adoptado las conductas necesarias para adaptarse al mundo exterior. Recien se atreverá a dar el gran salto para salir del cascarón cuando la realidad lo empuje a ello.

Además de nuestros protagonistas, la película también presenta un hermoso compendio de personajes secundarios con los rasgos característicos que el director desarrollaría en sus posteriores filmes, componiendo de esta manera su propio universo simbólico. En I vitelloni se presentan unos reconocibles esbozos de lo 'felliniano': las viejas señoras pomposamente vestidas y de miradas lapidarias en la estación, después del casamiento; la Roseta, aparentemente una prostituta a la que Alberto no puede dejar de molestar; la mujer seductora del cine, a la que Fausto no puede resistirse; el loco del pueblo, Giudizio, que nunca puede estar con la boca cerrada; las bailarinas y el extravagante artista 
homosexual; los niños, el del ferroviario y la hermana menor de Moraldo tienen la energía vital y la malicia propias de estos seres en la obra del autor. Estos son algunos de los personajes de infancia y juventud que tanto añora el director porque "no se trata de un autor biográfico, sino multibiográfico", según Truffaut.

La ternura que Fellini proyecta sobre sus personajes es contagiosa. Puede que actúen de manera vil en muchas ocasiones, como Fausto, pero es inevitable no sentir simpatía por ellos. Los seguimos en sus errores y sabemos perdonarlos cuando los reconocen; son como pequeñas criaturas, niños inconsecuentes y frágiles. La juventud errante se encuentra en un proceso de aprendizaje. Fellini no los juzga, los comprende, se divierte con sus travesuras. "No creo en los malvados, solo en las personas. Los buenos pueden comportarse con mucha maldad. Y un malvado puede ser víctima de circunstancias atenuantes, igual que un desalmado perverso puede enternecerse con el maullido de un gatito" (Wiegand, 2003). Alberto, el más burlón del grupo, es en realidad el más trágico: sin padre, vive mantenido por su madre y hermana. Esta última es quien sostiene el hogar y termina por abandonarlos en un día de fiesta. A pesar de ello, se resiste a cambiar de vida. No importa qué es lo que le suceda, siempre va a seguir 'jodiendo': la escena de Laboratori es una de las más divertidas y recordadas.

\section{Motivos}

“Los inútiles anticipa a los mejores fellinis. Su fluidez narrativa de pronto se abre a secuencias de gran calibre dramático, patéticas y hondas insinuaciones, bizarras mezclas de lo sórdido y lo sublime a lo que se suman algunos asomos de simbología" (Vivas, 1994) De los primeros filmes del autor, este es el que más pulpa tiene. Podemos reconocer las semillas de sus futuras obsesiones. Aquí van algunas:

Las fiestas, máscaras de la celebración de la vida, son constantes hasta el punto de convertirse en emblemas de la obra del realizador. En esta película hay tres y siempre acaban mal. El concurso de belleza al inicio del

\section{Dicen que Fellini} nunca fue un vitellone, que no pudo ser posible pues partió a Roma cuando tenía 19 años y no le dio tiempo para convertirse en uno de esos vagos de esquina. Sin embargo, cada uno de ellos es Fellini. filme sirve para presentar a los personajes y sus diversos matices. Una tormenta acaba con la felicidad del momento y presagia la primera mala noticia: Facundo, el primer modelo de mujeriego de Fellini, se entera de que será padre. Otra fiesta, un carnaval de disfraces en la que se resalta la figura del payaso, hace que el lado más patético de Alberto aflore y tome conciencia de su existencia. La última es una fiesta privada entre los protagonistas y las bailarinas del show del artista que admira Leopoldo. Fausto - el infatigable- hace de las suyas y provoca el conflicto que lo hará madurar: Sandra se escapa con el niño y le da una lección a su marido.

El mary su poder evocativo es otro de los motivos. A veces, seres insólitos surgen de él; otras, sirve para que sus personajes renazcan o se purifiquen. Los inútiles matan el tiempo y comparten sus ilusiones enfrente de él. Precisamente, esta imagen de los cinco juntos en el muelle sintetiza la temática principal: la juventud y su destino siempre incierto. El último encuadre del filme también subraya esta idea: Guido, el niño del ferroviario - espejo de Moraldo- , se balancea sobre una de las vías del tren.

Otro motivo es el silbido del viento. Este recurso, omnipresente, es bastante significativo en la obra fe-

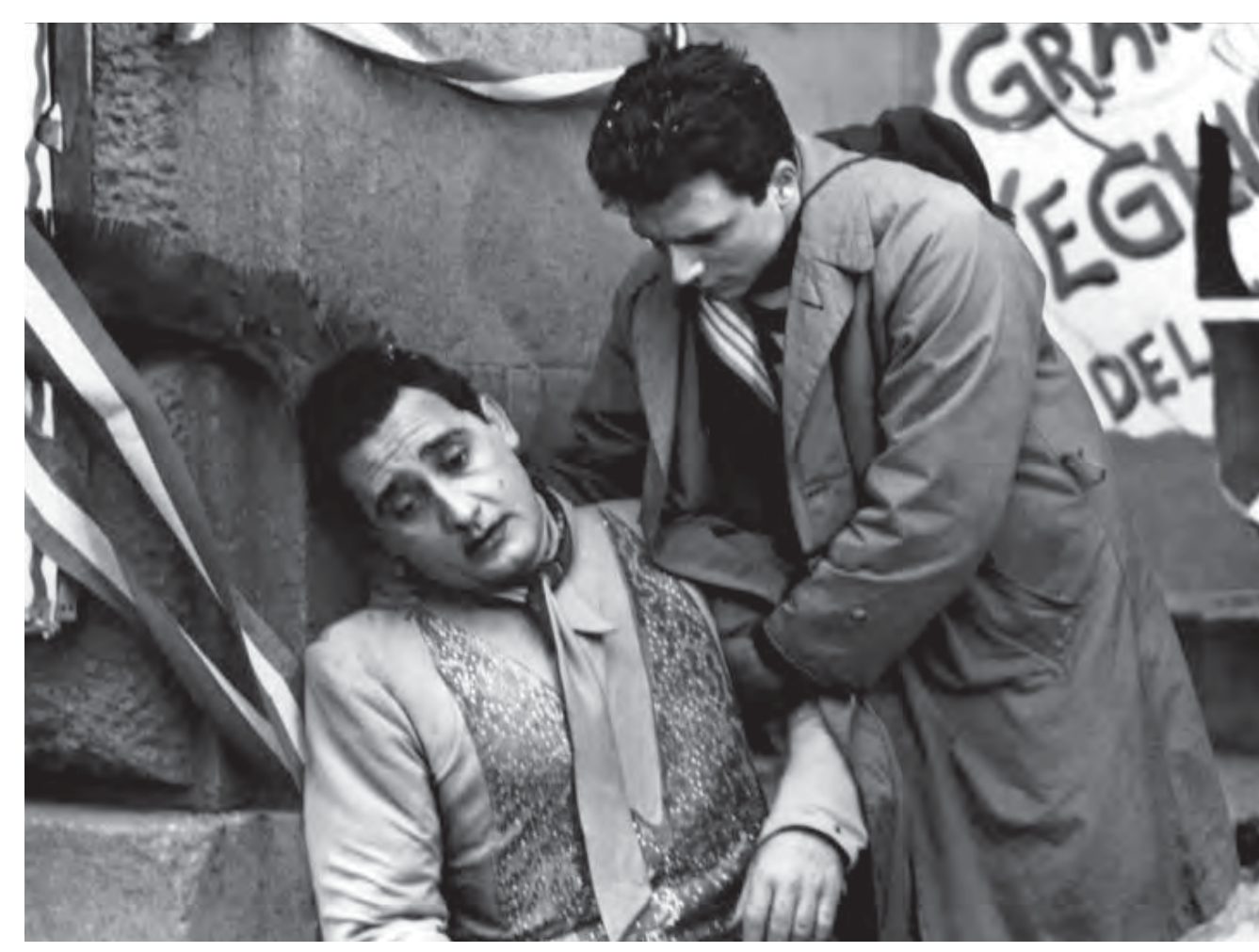




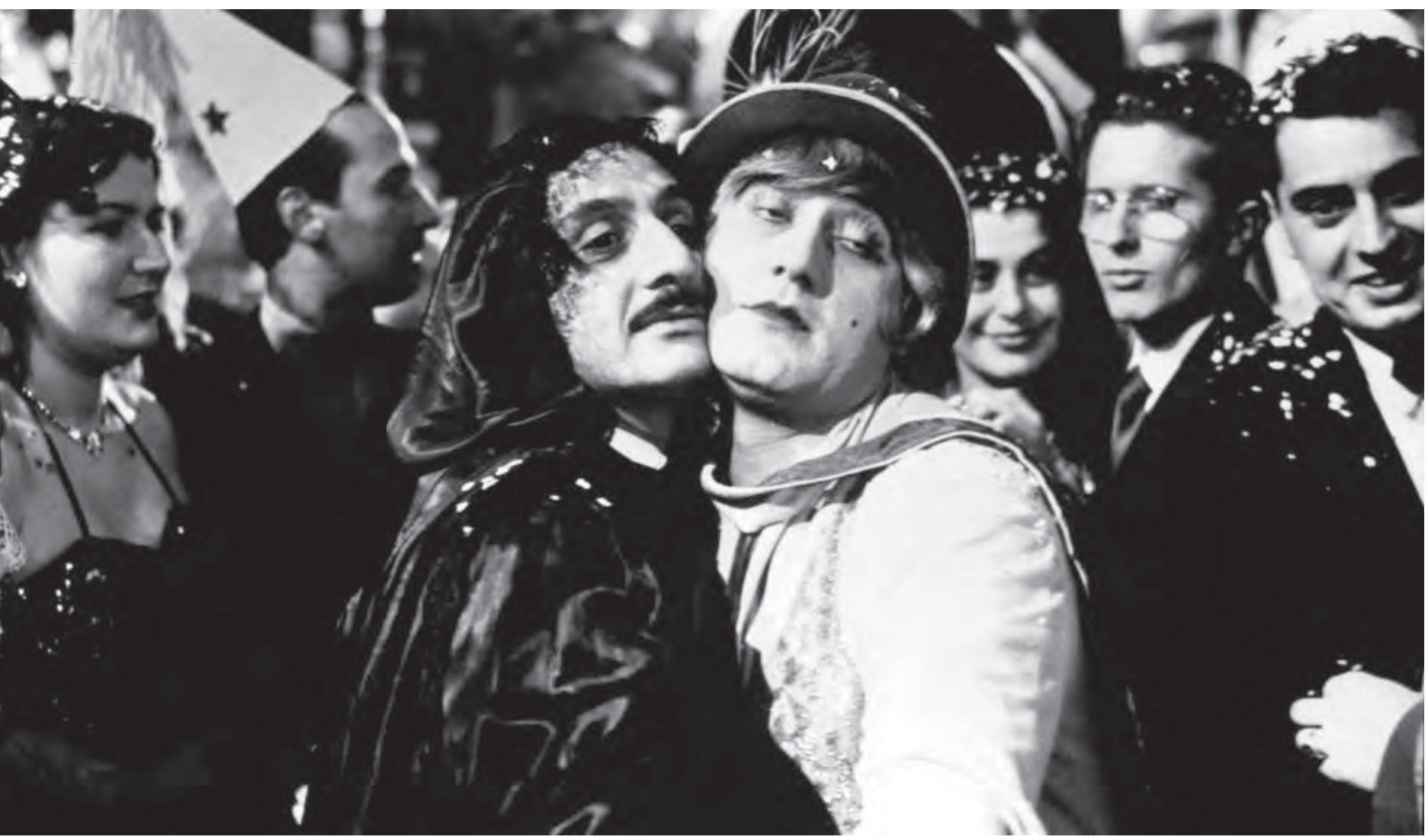

lliniana. Siempre nos anticipa un momento excepcional, cargado con el peso del misterio o la revelación. Uno de esos momentos se da cuando Leopoldo persigue a su ídolo en medio de un ciclón, por las calles vacías del pueblo. Desembocan en el puerto y el cantante se le revela con segundas intenciones que Leopoldo intuye homosexuales.

\section{Más allá de la realidad}

Existen instantes en I vitelloni en los que Fellini demuestra su inquietud por quererse desprender de las formas del neorrealismo ${ }^{1}$ para dar rienda suelta a su imaginación. Son fugaces, pero son. El primer momento se da en la playa. Es invierno y los amigos se reúnen en el muelle para fantasear acerca de su futuro. Los vemos de espaldas frenteal mar: el viento y la música envuelven la escena con un halo de misterioy, por un segundo, tenemos la impresión de que se trata de un sueño. No lo es, pero Alberto está a punto de enterarse de una mala noticia. El segundo momento es el baile de Fausto, cuando regresa de luna de miel con Sandra. Contentos con el reencuentro, Fausto decide enseñarles algunos pa- sos de moda que acaba de aprender en la ciudad. Lo hace en medio de la calle y toda nuestra atención es dirigida hacia él. Se trata de solo un momento porque Fellini recién ha comenzado a echar vuelo. El encanto que imprimen estas piezas musicales en sus películas es maravilloso. Recordemos a Cabiria bailando mambo o a Anita Ekberg celebrando al ritmo del rock and roll en La Dolce Vita (1959). Otro es cuando Alberto, vestido de mujer y borracho, se topa con una de la cabezas gigantes del carnaval. La figura del payaso, en lugar de evocarle algún tipo de celebración, lo termina por irritar y hasta la realidad sele termina desfigurando. Después de la fiesta, la pesadilla de la resaca lo invade y con ella todos sus miedos afloran: "No somos nada", le dice a Moraldo.

Es inevitable no ver en estas escenas la búsqueda de Fellini hacia 'algo más'. Otro momento, el de Giudizio, el loco del pueblo, es ejemplar. Sentado sobre la arena, se encuentra solo con la escultura de un ángel de madera. Se quita el gorro y lo contempla como si se tratase de un ángel de verdad. El ser marginal al lado de un figura celestial. Lo vulgar y lo sagrado en un solo encuadre.
Fellini se vio seducido de hacer una continuación de esta parábola de iniciación juvenil bajo el título de Moraldo en la ciudad. Lamentablemente, no lo dejaron. Ya conocemos el desarrollo de sus posteriores álter ego - solo que encarnados bajo los nombres de Marcello y Guido- en las que llegarían a convertirse en sus películas más famosas.

Recordemos que Fellini colaboró como guionista en un par de películas de Rosellini: Roma, ciudad abierta (1945) y Paisa (1946). En algunas entrevistas confiesa la admiración que sintió al ver cómo trabajaba el emblemático director italiano y que este influyó en su manera de hacer y ver las películas. Incluso, durante el rodaje de Paisa, Rosellini cayó enfermó y permitió que Fellini dirigiera una de las seis secuencias. La experiencia con Rosellini le permitió descubrir otros aspectos -la guerra y sus consecuencias- de la ciudad a la que pertenecía, dándole una mayor perspectiva de su entorno.

\section{Bibliografía}

Chandler, C. (1995). Yo, Fellini. Barcelona: Seix Barral.

Fellini, F. (1999). Hacer una película. Barcelona: Paidós.

Vivas, F. (1994). Adiós Federico. La gran ilusión, $42-43$.

Wiegand, C. (2003). Federico Fellini: el mago de los sueños 1920-1993. Colonia: Taschen. 